Documento

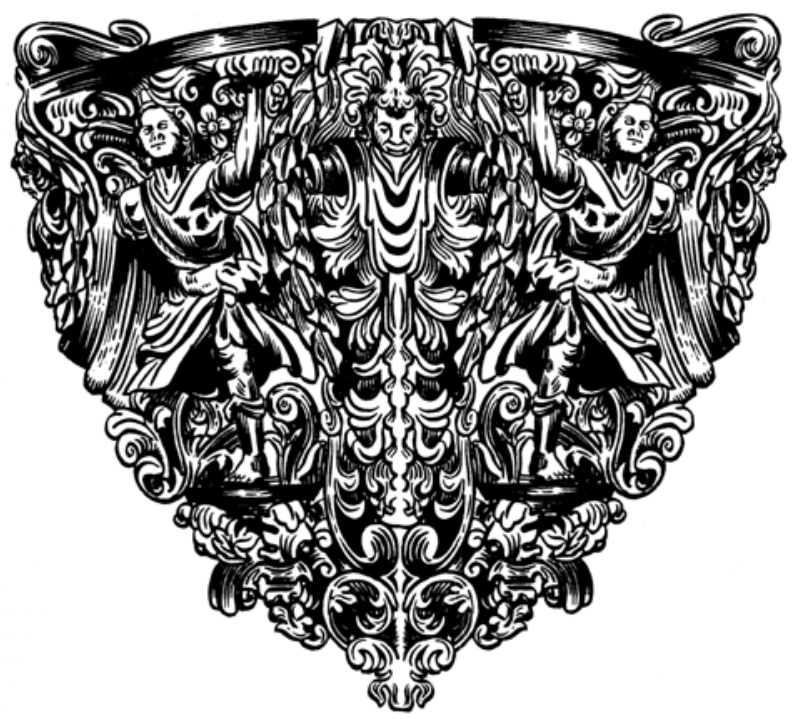




\section{Carta de don Cristóbal Millán de Poblete a Juan Díez de la Calle, con una relación de los ministros de la catedral de México (20 de mayo de 1647)}

\section{Guillaume Gaudin*}

UNIVERSIDAD DE PARÍS OESTE

El 20 de mayo de 1647, el medio racionero de la catedral de México Cristóbal Millán de Poblete $(† 1670)$ firmó una carta para el oficial mayor de la secretaría de Nueva Espańa del Consejo de Indias Juan Díez de la Calle (1598-1662). Eso explica que el documento publicado esté hoy ubicado en los manuscritos de la Biblioteca Nacional de Madrid entre la decena de legajos que pertenecen a los papeles de Díez de la Calle. En efecto, el oficial madrileño era muy aficionado a cualquier papel o descripción que se tratara de la plantilla eclesiástica o civil en las Indias occidentales. ${ }^{1}$ En 1647 , era ya autor de dos Memoriales, verdaderas listas de los empleados de la Corona en América y Filipinas. ${ }^{2}$ A pesar de su nivel medio en la jerarquía del Consejo de Indias (como oficial no era letrado), su obra y las huellas que nos quedan de sus relaciones con varios personajes importantes de las Indias occidentales demuestran su estatus de experto de las "cosas de Indias". Ahora bien, con el Patronato Real, el rey nombra-

*gaudin-senghor@laposte.net

${ }^{1}$ Jean-Pierre Berthe, "Las Islas Filipinas 'Tercer mundo', según don Francisco de Samaniego (1650)", en Estudios de historia de la Nueva España: de Sevilla a Manila, Guadalajara, 1994, 297-318.

${ }^{2}$ Juan Díez de la Calle, Memorial informatorio [... ] contiene lo que su Magestad provee en su Consejo, y Junta, y por las dos Secretarias de la Nueva España, y Pirú, Eclesiástico, Secular, Salarios, Estipendios, y Presidios, su Gente, y Costa, y de que Cajas, y Hazienda Real se paga: valor de las Encomiendas de Indios, y otras cosas curiosas, y necesarias, Madrid 1645; Memorial y Noticias Sacras y Reales de las Indias Occidentales [... ] comprehende Lo Eclesiástico, Secular, Politico, y Militar, que por fu Secretaría de la Nueva-España se prouee: Presidios, gente, y coftas, valor de las Encomiendas de Indios, y otras cofas curiosas, necesarias, y dignas de saberse, Madrid, 1646. 
ba a los clérigos y se encargaba de controlar el diezmo. Basta recordar que "los capitulares eran a la vez funcionarios de ese imperio [universal] y capellanes del rey católico". ${ }^{3}$ En el contexto de "urgencias financieras" de la Corona, Felipe IV y sus ministros procuraban enterarse de todos los asuntos de hacienda, incluso lo relativo al $\mathrm{Pa}$ tronato. ${ }^{4}$ Por eso Díez de la Calle estaba muy interesado en conocer con más precisión posible las prebendas y lo que costaban.

Este documento tiene un doble interés para la historia de las instituciones y para la historia de la circulación de los saberes en el marco de la monarquía católica. Por una parte, la relación de Cristóbal de Millán de Poblete entrega una tabla precisa de la plantilla y de la situación financiera de la "nueva" catedral de México a la mitad del siglo XVII. ${ }^{5}$ En este momento, la nueva catedral no estaba todavía consagrada o sea su fábrica material no estaba terminada: la primera consagración ocurrió en 1656. Por otra, la carta presentada es un maravilloso documento para ilustrar la circulación de la información entre Madrid y sus territorios americanos. En efecto, por un lado, el oficial busca sin descanso descripciones de las instituciones indianas, del otro, el medio racionero solicita una promoción a una canonjía y para ello se apoya en la oficialidad del Consejo de Indias ofreciéndole información. No se puede entender la circulación de la información sin relacionarla con el sistema político de las mercedes: el rey y su Consejo disponen del poder de nominación, en contraparte pueden exigir obe-

${ }^{3}$ Óscar Mazín, "El Cabildo Catedral y la investigación histórica”, Nelly Sigaut, ed., La Iglesia católica en México, Zamora, El Colegio de Michoacán, 2009, 145.

${ }_{4}^{4}$ Óscar Mazín, El Cabildo Catedral de Valladolid de Michoacán, Zamora, El Colegio de Michoacán, 1996, 187.

${ }^{5}$ La iglesia vieja fue demolida en 1626 por orden del virrey Marqués de Cerralvo. Desde 1626 a 1641 se celebraron los sagrados oficios en la sacristía recién terminada de la nueva catedral. La nave central estaba terminada y tres bóvedas procesionales cerradas. En los años 1640, existía una "pequeña catedral propicia a las ceremonias eclesiásticas". Así, el cronista real Gil González Dávila afirmaba en su Teatro eclesiástico de la Santa Iglesia de México que el obispo don Juan de Mañosca y Zamora "dejó acabado el edificio de su Iglesia catedral” en 1646. Véase Gil González Dávila, Teatro eclesiastico de la primitiva iglesia de las Indias Occidentales: vidas de sus Arzobispos, obispos y cosas memorables de sus sedes..., en Madrid: por Diego Diaz de la Carrera, 1649, fol. 66 y Manuel Toussaint, Iglesias de Mexico. La catedral de México, vol. 2, México, Publicaciones de la Secretaría de Hacienda, 1924, 24-25. 
diencia, pero también servicios como descripciones o informes. Individuos de segundo rango como Díez de la Calle y Millán de Poblete también se incluyen en esta compleja mecánica política imperial.

Cristóbal Millán de Poblete consiguió el grado de bachiller en 1628 , pero en varios documentos aparece como doctor. En los años 1640, es medio racionero del cabildo catedral de México, luego racionero "entero" en 1659 y por fin canónigo en 1662, muere el 6 de mayo de $1670 .{ }^{6}$ Hijo de Francisco Millán y María Ana de Poblete, una familia criolla de México, "apellidos antiguos y nobles, muchos hay de este linaje señalados en virtud y letras".?

La carta fue probablemente escrita en dos ocasiones debido a ciertas repeticiones y contradicciones (el autor admite que es una copia de una carta ya enviada una primera vez). Se compone de dos partes: primero, un texto de tres páginas que trata de las últimas noticias y solicita ayuda a Juan Díez de la Calle; segundo, una lista de cuatro páginas tituladas: "Rason de los ministros y sirvientes que la S[anta] Ig[lesia] metropolitana de mexico tiene, los salarios que ganan y de que genero se les paga y del salario de cada año de cada uno".

En la primera parte de la carta, don Cristóbal se pone claramente en situación de solicitante cuando pide la plaza del canónigo recién difunto Juan Nieto de Avalos. ${ }^{8}$ Aparte de las formulas de cortesía, el medio racionero no deja de ensalzar a Juan Díez de la Calle hablando de "su gran talento y capacidad de vuestra merced". Se dirige a él como "Secretario Juan Dias de la calle nuestro Señor" a pesar de que el oficial madrileño no llevaba este título. Mediante la retórica clásica, Millán de Poblete se queja de su pobreza para preparar su demanda. Las pruebas de sumisión marcan la carta y caracterizan una relación de patrocinio. Sin embargo, parece que Juan Díez de la Calle no le pudo ayudar mucho en esa ocasión porque don Cristóbal tuvo que esperar más de diez años antes de conseguir una ración entera. ${ }^{?}$

${ }^{6}$ Leticia Pérez Puente, Tiempos de crisis, tiempos de consolidación: la catedral metropolitana de la ciudad de México, 1653-1680, México, 2005, 300.

${ }^{7}$ Ibid., p. 87.

${ }^{8}$ AGN, Instituciones Coloniales, Regio Patronato Indiano, Bienes Nacionales (014), Volumen 56, expediente 39.

${ }^{9}$ Leticia Pérez Puente, op. cit., p. 300. 
Don Cristóbal es un intermediario de Juan Díez de la Calle en México porque transmite cartas a otras personajes como Diego Cervantes, mercedario, chantre de la catedral de Oaxaca. Otro chantre surge en la carta, ofreciendo chocolate al oficial madrileńo: pues desde 1645, el chantre de la catedral de México era Juan de Poblete, hermano de Cristóbal, también rector de la Universidad y según Leticia Pérez Puente "el personaje de mayor revelancia en el cabildo [...]" en los años 1650 (ocupó el deanato en 1657). Los hermanos Millán de Poblete se ilustraron dentro de la Iglesia hispanoamericana: el mayor fue también canónigo y dignatario de las iglesias de Puebla y México, profesor de teología en el seminario fundado por Juan de Palafox, luego arzobispo de Manila. Un sobrino, José Millán de Poblete, hizo una buena carrera eclesiástica en Filipinas. ${ }^{10}$ María de Poblete, hermana de Cristóbal y Juan, era también famosa por ser actriz de un milagro, fenómeno que empezó curiosamente el año siguiente a la carta de don Cristóbal: 1648. La fuerza y reputación del milagro de los panecitos ponen de manifiesto las extendidas relaciones de la familia en la capital novohispana. ${ }^{11}$ Por lo tanto, en la carta don Cristóbal critica la actitud de sus hermanos (particularmente Miguel) por no proveerle ayuda financiera. ${ }^{12}$

La segunda parte de la carta es una relación precisa y exhaustiva de los empleados del cabildo de la catedral de México, con sus salarios y el funcionamiento de la fábrica. No debe extrañarnos que no haya la lista de los canónigos, pues el Consejo de Indias (más precisamente la Cámara de Indias desde 1644) los nombraba y las cédulas se quedaban en las minutas del Consejo. Sin embargo, en Madrid no se conocía el conjunto de empleados de la catedral y tampoco las finanzas de la institución. Al leer la carta, nos damos cuenta que Juan Díez de la Calle pidió tales datos a su corresponsal mexicano. El oficial madrileño quedó tan satisfecho de este docu-

${ }^{10}$ Antonio Rubial García y María de Jesús Díaz Nava, “'La santa es una bellaca y nos hace muchas burlas' El caso de los panecitos de santa Teresa en la sociedad novohispana del siglo XvII", en EHN24, enero-junio 2001, p. 59.

${ }^{11}$ Ibid., p. 61.

${ }^{12}$ Sin embargo, Miguel de Poblete nombró en 1653 a su hermano Cristóbal, juez ordinario en el Santo Oficio, AGN, GD 61 Inquisición, vol. 86, exp. 162. 
mento que pensaba publicarlo integralmente en su obra maestra (pero nunca publicada), las Noticias Sacras y Reales de los dos Imperios de las Indias occidentales. ${ }^{13}$ Además el oficial del Consejo de Indias utilizaba otro modo para recoger y mejorar sus conocimientos. En la carta aparece que mandaba sus obras y pedía correcciones : "no es tanta la renta que tenemos como vuestra merced nos pone en su papel impreso" declara don Cristóbal. ${ }^{14}$ Para el prebendado es también una forma de curarse en salud.

Cada ministro del cabildo sale en una lista con su función, su salario en pesos y la renta sobre la cual se paga (gruesa, fábrica o cuatro novenos), desde el menor bordador (30 pesos cada año) hasta el mayordomo de la gruesa (dos mil pesos) pasando por el organista (mil pesos). En total, son noventa las personas que trabajan por la iglesia catedral: los que participan en el rito son 71 (incluyendo 27 ministros de la Capilla), trece son los que administran y seis son obreros y artesanos. Al final, varios "Indios y un negro esclavo" trabajan en la iglesia.

Por otra parte, don Cristóbal explica los gastos de la fábrica y la renta: nos damos cuenta del mecanismo financiero: el eje central es el diezmo rigurosamente dividido en cuartos, uno para el obispo, otro para el cabildo y dos cuartos restantes repartidos en nueve novenos. ${ }^{15}$ Otras rentas aparecen como "las casas y rentas" o el "diesmo del escusado del conde de Santiago" o "la tercia parte de la vacante de la quarta Arzobiscopal" ${ }^{16}$ o la cofradía del Santísimo Sacramento

${ }^{13}$ Biblioteca Nacional de Madrid (BNM), Ms 3023, fol. 131v.-133.

${ }^{14}$ En el Memorial de 1646, Juan Díez de la Calle afirma que la renta es de $24 \mathrm{mil}$ pesos, Díez de la Calle, op. cit., fol. 46v.

15 "Los diezmos de los obispados de las Indias se reparten en esta forma. Del que vale la gruesa $16 \mathrm{U}$ pesos al año lleva el Obispo $4 \mathrm{U}$ quatro el Cabildo Eclesiastico; los otros $8 \mathrm{U}$ se reparten en nueve novenos; noveno y medio lleva la fabrica de la Iglesia, otro tanto el Hospital, dos novenos Su Magestad (por concession Apostolica) y de los quatro novenos que quedan se pagan los Curas, y el Maestro de Capilla, Cantores, y Sochantre: Y el superavit (que es lo que sobra, pagado esto) se acrecienta en la mesa Capitular y reparte a los Prebendados", Díez de la Calle, op.cit., 1645, fol. 14.

${ }^{16}$ Las vacancias a pesar de ser un problema por la buena administración tanto religiosa como civil de las posesiones americanas, aparecen como un recurso financiero muy utilizado en las gratificaciones reales pero también en la paga de los prelados por el rey. En los años 1630, la Corona en la búsqueda de todo tipo de recursos financieros procuró 
de la catedral que paga una buena parte de la cera gastada. Millán de Poblete se queja de las variaciones de la renta y su disminución. En sus Noticias Sacras y Reales, Díez de la Calle reproduce a continuación de la carta de Millán de Poblete una lista de "Rentas y gastos que tuvo la fabrica el año de 1645" (la reproducimos al fin del documento): las rentas de la fábrica rinden 14,723 pesos y los gastos son de $16,682 \ldots$

Don Cristóbal acusa dos veces al clero regular y más especialmente a los jesuitas. Con Óscar Mazín recordamos que "los años 1640 fueron determinantes para las iglesias catedrales tocante a ese viejo litigio contra las órdenes" ${ }^{17}$ Aquel año de 1647, precisamente en los meses de marzo-junio, culminó el violento conflicto entre los jesuitas y el obispo de Puebla, Juan de Palafox. ${ }^{18}$ En marzo, el obispo de México, Mañosca, eligió a dos frailes dominicos favorables a los jesuitas como jueces conservadores para resolver la disputa entre $\mathrm{Pa}$ lafox y la Compañía. El medio prebendado, Millán de Poblete no se atreve a tratar de esas noticias calientes y tan polémicas, por lo tanto, parece elegir el campo “antijesuita”. Sabemos que Juan de Palafox fracasó a corto plazo y tuvo que volver en España en 1649. Sin embargo, diez años más tarde encontramos en los papeles de Juan Díez de la Calle una sentencia impresa del Consejo de Indias titulada Sentencias de vista y revista pronunciadas por el Supremo Consejo de las Indias a favor de las Santas Iglesias Metropolitanas, y Cathedrales deIlas, y del Real Fisco, en el pleyto que siguieron con las Sagradas Religiones sobre la paga de los Diezmos, fechada del 16 de junio $1657 .{ }^{19}$ Pues se les obligaba a las órdenes religiosas a pagar el diezmo.

recuperar para la caja real el tercio de la cuarta episcopal vacante lo que provocó tensiones, véase Óscar Mazín, op. cit., 1996, 187.

${ }^{17}$ Óscar Mazín, op. cit., 1996, 182.

${ }^{18}$ Antonio Ybot León, La Iglesia y los elesiásticos españoles en la empresa de Indias, Barcelona, Salvat Editores, vol. 2, 1962, 934-941.

${ }^{19}$ BNM, Ms 3024, fol. 426-427. 


\section{Documento}

Biblioteca Nacional de Madrid, Ms 3048, fol. 176r.-178v.

//fol. 176r.//

Secret[ari]o Juan dias de la calle mi S[eño]r

E recibido las que $v$ [uestra] $m$ [erce]d me a hecho $m$ [erce]d de escribirme en los avisos que an llegado a estos reynos con la estimacion que debo dar a las honras y favores que $\mathrm{v}$ [uestra] $\mathrm{m}$ [erce] $\mathrm{d}$ me hace siempre, como por las buenas nuevas que me da de su salud y la de esa $S$ [eñora] mia d[oña] Angela que conseda n[uest]ro S[eño]r a vmd se an cumplido como se lo deseo a cuyo servicio quedo tan obligado como debo. En la armadilla recibi dos pliegos de v[uestra] $\mathrm{m}$ [erce]d en el uno, una muy breve de 5 de mayo en que me dice $\mathrm{v}$ [uestra] $\mathrm{m}$ [erce]d me tiene escrito largo y aunque me dice $\mathrm{v}$ [uestra] $\mathrm{m}$ [erce] $\mathrm{d}$ me tiene escrito largo, recibi otro pliego grande con algunas cartas del memorial impreso, no vino en él carta ninguna de $\mathrm{v}$ [uestra] $\mathrm{m}$ [erce]d que por la letra y memorial conoci ser suyo, luego al punto di las cartas a sus dueños. Y deseo todos respondan a $\mathrm{v}$ [uestra] $\mathrm{m}$ [erce]d porque conosca la puntualidad con que le servi. $\mathrm{Vi}$ el memorial impreso y lo e dado a todos los amigos para que lo lean. Y se lo alabo mucho a v[uestra] $m$ [erce]d porque de verdad esta muy bueno. Y muy como de su gran talento y capacidad de $\mathrm{v}$ [uestra] $\mathrm{m}$ [erce]d, y las noticias de el son tales que otro que $\mathrm{v}$ [uestra] $\mathrm{m}$ [erce]d que tan individualmente trata las materias y que a costa de mucho sudor, y trabajo ajusto las cosas de el, no pudiera aver salido con tan grande empeño, mucha $\mathrm{m}$ [erce]d hace $\mathrm{v}$ [uestra] $\mathrm{m}$ [erce]d a esta S[ant]a Iglesia en la renta de ella, porque como aora vera $v$ [uestra] $m$ [erce]d por certificacion que se enbia al consejo, no es tanta como v[uestra] $\mathrm{m}$ [erce]d presume, que yo no se como nos sustentamos con tan cortas rentas, y mas los pobres a quien costo el ir a Espańa por ellos. Y nos duran todavia los empeńos con que venimos de alla, y vamos cada dia en gran diminucion, asi por estar la tierra apurada, y acabada, porque las religiones se van apoderando 
de las haciendas //f. 176v.// Y si esto no se ataja se an de quedar las Yglesias sin diezmos que es la renta dellas, y el culto divino asistimos a de perecer y faltar y sera costoso buscar con que sustentarnos.

Remito a v[uestra] $\mathrm{m}$ [erce]d individualmente la me[mori] a que me pide, ajustada lo mas que a sido posible en lo demas que v[uestra] $\mathrm{m}$ [erce]d me pide no a sido posible en esta ocasion porq[ue] es nec[esari]o mucho tiempo $\mathrm{p}$ [ar] a revolver los libros y papeles porque todo esta sin orden..$^{20} \mathrm{Y}$ van en la primera ocasion sup[lic] o a $\mathrm{v}$ [uestra] $\mathrm{m}$ [erce]d me haga $\mathrm{m}$ [erce] d de continuar el favor que me a enpezado a hacer de remitirme los papeles que imprimiese por ser de toda estimacion para mi.

El lo que v[uestra] m[erce]d me mando cerca de $\mathrm{D}$ [on] $\mathrm{Al}$ [onso] de Careaga , le tengo escrito a guaxaca a donde reside y remitido la carta que v[uestra] $\mathrm{m}$ [erce]d me envio para el que con la q[ue] tanbien vino para el chantre, no me an respondido y asi no puedo dar por aora a $\mathrm{v}$ [uestra] $\mathrm{m}$ [erce]d mas noticia.

En el particular de mis comodidades no tengo que decir a v[uestra] $\mathrm{m}$ [erce]d mas de q[ue] ya se hara de ver la cortedad y necesidades con que lo pasare con las obligaciones de la Prebenda y la mucha cortedad de esta pues sabe $v$ [uestra] $m$ [erce]d quan debido era que mis her[man]os me ayudasen, ellos se hallan muy bien acomodados a costa de mi misma sangre y hacienda, y yo desacomodado, atrasado, imposibilitado y pobre sin tener en ellos ayuda ninguna, ni aun agradecimiento, ni corespondencia piensan por si se lo merecieron todo, y no tengo en ellos mas de un enemigo en cada uno, que esto grangee en lo que por ellos hize, yo no merezco mas. Ya si me consuelo con mi fortuna, desdicha, y pobreza, y vivo con el mayor desconsuelo del mundo, con q[ue] no me queda mas recurso que pedir y suplicar a v[uestra] $\mathrm{m}$ [erce]d se acuerde de mi, y en las ocasiones

${ }^{20}$ Es posible que a semejanza de las "Relaciones geográficas" de 1648, Juan Díez de la Calle transmitió a su corresponsal en México un cuestionario donde le pedía recoger informaciones en los archivos del cabildo. 
que se pueden ofrecer me honre, y haga $\mathrm{v}$ [uestra] $\mathrm{m}$ [erce]d como quien es continuando las que e recibido de su mano, que bien puede fiar de mi le sere siempre agradecido, y deseare toda mi vida servirle lo mucho que le debo cuya vida guarde Nuestro S[eñor] a v[uestra] $\mathrm{m}[$ erce $] \mathrm{d}$.

Esto es copia de lo que tengo escrito a v[uestra] $\mathrm{m}$ [erce]d en los avisos, y armadilla, y cierto estoy corridisimo de ver, que salga una flota, ${ }^{21}$ y yo este tan pobre y sea tan desdichado que no me sea posible enbiar a v[uestra] $\mathrm{m}$ [erce]d en ella un poco de chocolate, de que pido a $\mathrm{v}$ [uestra] $\mathrm{m}$ [erce] $\mathrm{d}$ mil perdones, pero $\mathrm{v}$ [uestra] $\mathrm{m}$ [erce]d manija las cosas, y asi no necesitare de darle mas satisfaccion de que ve y conoze lo que es una media racion, pues no a pasado este ańo de treçientos pesos la renta, ${ }^{22}$ la cosa mas lastimosa que se puede decir, y vera $v$ [uestra] $m$ [erce]d las obligaciones que a de sustentar un hombre de bien, yo tenia, mis esperanzas en mis hermanos, al de la Puebla no debo un socoro de diez pesos. El chantre me ofrece y dice envia a v[uestra] $\mathrm{m}$ [erce] $\mathrm{d}$ en mi nombre chocolate porque sabe mi pobreza, y que yo no lo puedo hacer, yo se lo e agradecido mucho. //f. 179r. // porque de verdad quedo muy corrido y crea v[uestra] $\mathrm{m}$ [erce]d, no es ni a sido por falta de voluntad ni obligaciones que confieso a v[uestra] $\mathrm{m}$ [erce]d, ni que dejo de tener muy presentes las fianzas y obras que a $\mathrm{v}$ [uestra] $\mathrm{m}$ [erce]d debo, pero no se si creera $\mathrm{v}$ [uestra] $\mathrm{m}$ [erce]d la pobreza y necesidad en que me hallo, causada del desamparo que mis her[man]os, que tambien me lo deben me an hecho todo esto le represento a v[uestra] $\mathrm{m}$ [erce]d pidiendole mil perdones y se suplico de nuevo, que mientras pueda, y Dios es servido de mejorar mi fortuna no me desampare, sino que en las ocasiones que se ofrecieren como lo sera la presente con la muerte de Juan Nieto de Abalos y aunque va en las nominas de las canongias en

${ }^{21}$ Se mandaban dos veces las cartas para asegurarse de su llegada. La carta de Millán de Poblete llegó con la flota de Nueva Espańa y Tierra Firme el 26 de agosto de 1647 en Cadiz.

${ }^{22}$ Díez de la Calle menciona 600 pesos a propósito del salario de los medio racioneros de México. Cf. Díez de la Calle, op. cit., 1645, fol. 10v. 
primer lugar D. Antonio de Esquivel ${ }^{23}$ sea servido de honrarme y hacerme todo favor que de nuevo le prometo a v[uestra] $\mathrm{m}$ [erce]d serle siempre (como lo confieso) muy obligado, reconocido, y agradecido y que algun dia le e de pagar lo mucho que le debo.

Escribime de guaxaca D[on] $\mathrm{D}$ [ieg]o de Cervantes el chantre aver recibido las cartas de $\mathrm{v}$ [uestra] $\mathrm{m}$ [erce]d que le remiti y dado en mano propria su pliego a $\mathrm{D}$ [on] $\mathrm{Al}$ [onso] de Careaga, y que en esta flota yra razon y respuestas de todo, y asi a sido v[uestra] $\mathrm{m}$ [erce]d servido en lo que me mando.

Y un otra vez con esta los papeles y mem[ori] as que v[uestra] $\mathrm{m}$ [erce]d me pidio que los e deseado ajustar lo mas que a sido posible, esto es en q[uant]o a los sirvientes, gastos, y ventas de la fabrica, va todo por menor y un año ajustado por las quentas de la renta y gastos para que $\mathrm{v}$ [uestra] $\mathrm{m}$ [erce]d se valga de lo que le fuese mas a proposito $=\mathrm{En}$ quanto a los alajas de la yglesia no me a sido posible ajustar con claridad y distincion la relacion y mem[or]ia de ellas porque estan tan sin orden que no es posible darselo: ni los libros, ni memorias parecen, con todo la quedo haciendo para remitirsela a v[uestra] $\mathrm{m}$ [erce]d y como esta yg[lesi]a esta tan en sus principios y la fabrica de ella es tan sumamente pobre, son muy pocas las alajas que ay de consideracion para poder hacer cuerpo de ellas, antes las pocas que oy ay van en grandicima diminucion con el continuo servicio, porque como se hacen por q[uen] ta de la fabrica y esta no tiene sustancia, no se pueden acrecentar ningunas, y sirviendo de ordinario las que ay estan todas rotas, acabadas y consumidas como lo estamos tambien los que servimos a la Y[glesi]a por su mucha cortedad y los pocos diesmos que tiene este arçobispado, no se ofrece o poca cosa mas de que Nuestro Señor me guarde a v[uestra] $m[$ erce]d muchos años para que yo le sirva lo que le debo y los favores que espero de su mano, cuya vida y salud sea la que yo le deseo, Mexico mayo 20 del 647.

${ }^{23}$ Don Antonio de Esquivel Castañeda, racionero de la Catedral de México desde 1628, rector de la Universidad de México (1641), muere en 1667, no obtuvo canonjía. En 1647, Ińigo Cuevas y Zuñiga se vuelve canonigo. Leticia Pérez Puente, op. cit., p. 299. 
Muy de v[uestra] m[erce]d su capellan y serv[id]or

D[on] [Cris]tobal Millan de Poblete [rúbrica]

// fol. 177r.//

Razón de los ministros, y sirvientes que la S[an]ta Iglesia metropolitana de Mexico tiene, los salarios que ganan y de que genero se les paga, del salario de cada ańo de cada uno.

Maestro de ceremonias 400 pesos en fabrica U400 pesos Sustituto de Maestro de Ceremonias 70 pesos en U70 pesos fabrica

Dos Sochantres a 200 pesos cada uno en fab[ric]a U400 pesos Once capellanes de choro a 166 pesos cada uno cada año los 130

pesos en fabrica, y lo demas en cuatro novenos

$1 \mathrm{U} 826$ pesos $\mathrm{m}$ [ont] an todos

Seis del choro, todos seis tienen 120 pesos de salario cada año en 4 novenos

U120 pesos

Cinco curas a 106 pesos cada uno en 4 novenos U530 pesos $\mathrm{m}$ [ont]an

Dos ayudantes de curas, y un cura de noche a estos pagan los curas de sus subvenciones U530 pesos Ocho acolitos a 100 pesos cada uno en fab[ric]a U800 pesos Apuntador $^{24} 120$ pesos de salario cada año los 55 pesos en fab[ric]a, los demas en 4 noveno U120 pesos Sacristan mayor 600 pesos de salario los 460 pesos en fabrica, los demas en 4 nov[eno]

24 "Es nombre de oficio, como el que está destinado en las Iglesias catedrales [...] para apuntar los que residen, asisten o faltan, para saber lo que ganan, o pierden [...]", Diccionario de autoridades, 1726. 
Sacristan menor 200 pesos de salario en fab[ric]a U200 pesos Chorista 100 pesos cada año en fab[ric]a U100 pesos Pertiguero $^{25} 326$ pesos de salario los 306 en fab[ric]a lo demas en 4 nov[eno].

Organista mil pesos de salario en fab[ric]a U326 pesos Maestro de ynfantes 200 pesos de salario en fabrica Relojero 150 en fab[ric]a $1 \mathrm{U}$ pesos Platero Francisco Dena para limpiar la plata 100 U200 pesos U150 pesos pesos en fab[ric]a

De labrar la ropa de la Sacristia 150 pesos cada año U150 pesos en fab[ric]a

Aderesador del reloj Juan Vital 40 pesos U040 pesos Obrero de la yglesia Francisco de Pareja 250 pesos en U250 pesos fab[ric]a

Mayordomo de la fabrica, el cap[itá]n Gabriel de la cruz

700 pesos de salario en fabrica

U700 pesos

Bordador Diego de Barrientos 30 pesos cada año en U030 pesos fab[ric]a

//fol. 177 v.//

La Capilla tiene los ministros sig[uien]tes ganan todos los salarios en fabrica y cada uno gana cada año el salario sig[uien]te

Maestro de capilla L[icencia]do Luys coronado gana 500 pesos Sustituvo de M[aestro] L[icencia]do Melchor 250 pesos de los Reyes L[icencia]do

Nicolas crespo

100

25 "Ministro secular en las Iglesias Cathedrales que asiste acompañando a los que ofician en el altar, choro [...]" Ibid. 


$\begin{array}{lll}\text { L[icencia]do } & \text { Melchor de herrera } & 300 \\ \text { L[icencia]do } & \text { Tomas Lopes } & 100 \\ \text { L[icencia]do } & \text { Agustin de Salazar } & 100 \\ \text { L[icencia]do } & \text { Andoval de Leon } & 150 \\ & \text { Francisco de Zuniga } & 150 \\ & \text { Juan de Zuniga } & 200 \\ & \text { Juan de Mayo } & 050 \\ & \text { Ambrosio de Solis } & 250 \\ \text { L[icencia]do } & \text { Nicolas de Leon } & 050 \\ \text { L[icencia]do } & \text { D Francisco de Monrroy } & 200 \\ \text { L[icencia]do } & \text { Joseph de Esquibel } & 300 \\ \text { L[icencia]do } & \text { Bartolome de quebedo } & 100 \\ & \text { Bernabe de Isla } & 100 \\ & \text { Joseph Coronado } & 050 \\ & \text { Joseph de Loaysa } & 100 \\ & \text { Francisco Arias } & 150 \\ & \text { Pedro de Prado } & 050 \\ & \text { Diego Peres } & 100\end{array}$

Ministriles de la capilla :

Joseph Juares

200 pesos

Alonso Asencio

150

Lazaro rodriguez

200

Diego Antonio

150

Juan de Ortega alcacar

250

Otro Juan de Ortega

200

Sigense aora los demas ministros que tiene la Iglesia todos los quales se pagan sus salarios de la gruesa y por si v[uestra] $\mathrm{m}$ [erce]d quisiere saber los que son, y lo que ganan lo pongo aqui por menor con los salarios de cada uno cada año. 
Correo mayor $\mathrm{P}^{\circ}$ Dias de la barrera U050

Contador mayor Ambrosio de madrid y ponerau U600

Contador menor y oficial de la contaduria Alonso deU300 la Peña

//fol. 178r.//

Abogado L[icencia]do D. Maseo de Figueros U150

Otro Abogado D. Juan de Arse U050

Secretario del cavildo Diego de villegas U200

Procurador Lucas de medina

U100

Solicitador y notario de la contaduria Diego de la Be-U200 navente

Escrivano Pedro moreno de Velasco

Mayordomo de la gruesa Joseph de la Cruz

Tiene la gruesa por mayor cada año entrando los salarios de arriba de ocho a diez mil pesos de gastos, en los ministros y administradores de los diesmos y cobradores, los quales se bajan de lo que monta la gruesa, que se llaman costas generales de gruesa $=$

Tiene la fabrica de gastos ordinarios (sin los extraordinarios que se suelen ofrecer) de cera, vino, hostias, y todos los demas gastos de la Sacristia, Indios y un negro esclavo de la Iglesia que asisten a ella, casi seis mil pesos cada ańo, que por ser unos mas que otros no se puede ajustar por menor.

La renta de la fabrica no tiene punto fijo, porque lo mas considerable de ella esta en su noveno y medio que tiene en la gruesa que conforme valen los diesmos asi crece, o baja, porque en sus casas y rentas, que algunas veces se arriendan y mucho tiempo suelen estar vacias pagando las rentas de ellas tendra hasta cinco mil pesos sin novecientos pesos en que esta oy rematado el diesmo del escusado 
del conde de S[an]tiago que toca y pertenece a la fabriqua = Y para los gastos que tiene tan considerables como se ve en la memoria de atras, lo que la remédia y reduce es la tercia parte de la vacante de la quarta Arzobispal que su Magestad le hace $\mathrm{m}$ [erce]d y esto es quanta noticia puedo dar a v[uestra] $\mathrm{m}$ [erce]d por menor en quanto a la fabrica y ministros de la yglesia $=$

Advierto a v[uestra] $\mathrm{m}$ [erce]d que no entra en esta memoria el gasto de la cera y aceite del S[antisi]mo Sacra[men] to porque esto corre por la cofradia del S[antisi]mo Sacra[men] to que esta fundada en dicha Iglesia, la qual pone la cera toda la octava de Corpus, el jueves Santo en el monumento y todos los domingos que es el tercero domingo de cada mes, que llamamos del S[antisi] mo Sacra[men] to y es muy gruesa la contaduria de cera que se gasta, que corre por la dicha cofradia, y del aceyte de dos lamparas q[ue] arden todo el año, la una en el altar mayor y la otra en la capilla del sagrario.

\section{//178v.//}

En quanto a lo demas en el punto de la renta de la gruesa se enbia testimonio de lo que a valido seis años ${ }^{26} \mathrm{y}$ como esta a de pasar en manos de v[uestra] $\mathrm{m}$ [erce]d me remito a ella donde lo vera por testimonio, y que aviendo avido dos ańos solos muy graves por el valor de los diesmos, los demas an sido tan vajos que la renta es tan corta como individualmente lo vera $\mathrm{v}$ [uestra] $\mathrm{m}$ [erce]d, y no es tanta la renta que tenemos como $\mathrm{v}$ [uestra] $\mathrm{m}$ [erce]d nos pone en su papel impreso, y lo peor es y lo mas sensible, y considerable, que cada año vamos en diminucion demas de mil pesos de vaja, de las haciendas que las religiones, y particularmente la de la compañia de Jesus nos quitan apoderandose de todas las haciendas sin pagar diesmos que es nuestro comer con que si Dios no remedia esto, y el consejo con su piedad lo ataja an de quedar las Iglesias todas, y particularmente esta sin diesmos, ni renta con que sustentarse los pre-

${ }^{26}$ Este testimonio no se encuentra en los papeles de Díez de la Calle conservado en la Biblioteca Nacional de Madrid. 
bendados, que estan en el choro sirviendo a dios de ministros, y a su Magestad de capellanes, y abra su Magestad sustentar los de su hacienda como lo hace en otras Yglesias.

//B.N.M, Ms 3023, fol. 133// [Documento añadido por Díez de la Calle en el manuscrito de sus Noticias Sacras y Reales]

Rentas y gastos que tuvo la fabrica [de la catedral de México] el año de 1645

Rentas:

De censos perpetuos

De censos redimibles

1382 pesos

Possessiones en la Plaza

1805

Arrendimiento de Cassas

2993

De los aniversarios

1843

Del noveno y medio

300 pessos

Del escussado del Conde de Santiago

5500 pesos

Que todo importo $14 \mathrm{U} 723$ pessos

900 pesos

Gastos:

De salarios a los Ministros de la Yglessia

$10 \mathrm{U} 500$ pessos

De censos que paga

1382 pessos

De cera

$2 \mathrm{U}$ pessos

Gastos de la Sachristia

2U800 pesos

Ymporta todo 16U682 pessos de forma que este año montó el gasto más que la renta 1859 pessos. 